\title{
Lecturas televisivas de la Transición: Informe Semanal y las primeras efemérides del Cambio
}

\author{
Virginia MARTín JimÉNEZ \\ Universidad de Valladolid \\ virgimj@hmca.uva.es
}

\begin{abstract}
Resumen:
Informe Semanal, el espacio informativo de Televisión Española nacido en 1973, se consolidó durante la Transición democrática. Teniendo en cuenta la importancia de este programa, este artículo busca analizar las lecturas televisivas que este informativo ofreció con motivo de las primeras efemérides de la Transición que se celebraron durante el transcurso de la misma.

Para ello se utilizarán, como fuente principal, las emisiones de Informe Semanal que se conservan en el Archivo de TVE, junto con las entrevistas personales a varios de los periodistas que formaron parte de su equipo y una actualizada bibliografía.
\end{abstract}

Palabras clave: Informe Semanal; Televisión Española; Transición democrática; Cadena pública; TVE;Eventos mediáticos.

\section{TV readings from the Spanish Transition. Informe Semanal and the first ephemeris of Change}

\begin{abstract}
:
Informe Semanal, the Spanish Television news program that was born in 1973, consolidated during the transition to the democracy. Given the relevance of this program, this paper analyzes the readings that this informative television offered for the first ephemeris of the Transition. This study is based on the analysis of Informe Semanal, in-depth and face-to-face interviews with journalists who lived through the transition in Spain and an updated bibliography.
\end{abstract}

Key Words: Informe Semanal; Spanish Television; Democratic transition; state television; TVE; media events.

\section{Referencia normalizada:}

Martín Jiménez, V. (2014): Lecturas televisivas de la transcición: Informe Semanal y las primeras efemérides del cambio. Historia y Comunicación Social. Vol. 19. Núm. Especial Marzo. Págs. 167-174.

Sumario: 1. Introducción. 2. Informe Semanal o la llegada del cambio a TVE. 3. Las efemérides políticas narradas por informe semanal. 4. Conclusiones. 


\section{Introducción}

Pocos años antes de que el franquismo llegara a su fin, la cadena pública (Televisión Española) aprobó un proyecto informativo realmente novedoso - Informe Semanal- que, a día de hoy, tras cuatro décadas en antena ha pasado a ser el programa televisivo más longevo de los que se han emitido en España. Desde 1973, cada sábado la televisión estatal presentaba a través de reportajes las noticias más destacadas que habían sucedido a lo largo de la semana; tratando de ofrecer al telespectador contenidos novedosos y con un enfoque más plural del habitual en la televisión estatal del final de la dictadura.

Informe Semanal se consolidó durante la Transición democrática y fue evolucionando durante los años en los que TVE contó con el monopolio en su ámbito mediático. Teniendo en cuenta el significativo lugar que ocupa en la historia de la televisión en España, este trabajo se centra en analizar qué tratamiento informativo otorgó este espacio al primer aniversario de algunos ejemplos de los principales hitos políticos que jalonaron el discurrir del inicio del cambio democrático, con qué enfoque se trataron estos acontecimientos y cómo, a través de estos reportajes la cadena pública fue desarrollando un discurso de la democratización del país que lo convirtió en un narrador oficial de la Transición.

La fuente principal de este trabajo será, junto con una actualizada bibliografía, las emisiones de Informe Semanal que se conservan en el Centro de Documentación de TVE y que fueron visionadas por la autora de estas páginas a partir de un planteamiento metodológico cualitativo de análisis de contenido.

\section{Informe Semanal o llegada del cambio a TVE}

A mediados de 1976 el programa Informe Semanal tuvo que enfrentarse al profundo cambio televisivo (como consecuencia del cambio político) que iba a traer consigo la llegada de Rafael Ansón Oliart a la dirección general de RTVE. El nombramiento de un nuevo director general vino acompañado de una remodelación de los programas informativos de la cadena estatal. Sin embargo, debido al carácter novedoso y, en muchos aspectos, rupturista de Informe Semanal, este quedó al margen de ese "cambio de imagen" de la televisión pública y continuó sus emisiones sin modificar el formato y sin que se produjeran variaciones en su dirección. Así pues, Pedro Erquicia se mantuvo al frente del programa, que continuó emitiendo sus reportajes semanalmente en su puesto habitual de la parrilla: los sábados en horario nocturno de prime-time en el Primer Canal (primera cadena).

Informe Semanal se había labrado una imagen de un programa con una plantilla de jóvenes profesionales que cada sábado trataba temas de actualidad desde una perspectiva diferente y, por ese motivo, en el imaginario colectivo no estaba ligado a la propaganda del régimen franquista y gozaba de gran credibilidad y apoyo por 
parte del público. Todo ello favoreció que su influencia y repercusión en la audiencia fuera más intensa que la de otros espacios informativos de la cadena estatal (Martín Jiménez, 2013. Pág.102).

Durante la Transición, y como una prolongación de los primeros años de emisión, el rostro más popular del espacio de Erquicia continuó siendo Rosa María Mateo; quien cada fin de semana presentaba a los telespectadores los reportajes elaborados por un equipo formado por periodistas como Miguel Cruz, Sol Alameda, Carmen Sarmiento, Ana Cristina Navarro, Ramón Colom, David Solar, Rafael Martínez-Durbán, Baltasar Magro, Manuel Rubio o Mercedes Milá y montadores como José Eloy Pareja, J. Benito Fernández o Nicolás Muñoz.

En la dirección encontramos, como hemos señalado anteriormente, a Pedro Erquicia, responsable del nacimiento de Informe Semanal hasta que abandona este espacio en septiembre de 1978 al marchar como corresponsal a Nueva York. Rafael Martínez-Durbán, miembro del equipo con el que se puso en marcha este informativo en 1973, se queda al frente del espacio hasta que, a finales de 1981, cede su puesto a uno de los redactores más antiguos de este informativo, Ramón Colom.

En los inicios de la Transición, el trabajo en equipo que traía consigo la elaboración de este espacio, se conformó en torno al "tándem guionista-realizador"; en el que el periodista-guionista era el responsable de recopilar los datos y de redactar el guión, mientras que el realizador se encargaba de la narración en imágenes. Ambos, guionista y realizador, dejarían la impronta de su trabajo firmando conjuntamente la mayor parte de los reportajes que emitió desde entonces Informe Semanal (Magro, 2003. Pág.46).

A finales de los setenta se van a producir también cambios en el estilo de la manufactura de los reportajes puesto que el periodista va perdiendo protagonismo en la información. Así,

Su impronta aparecerá tan sólo en la lectura de los textos en off y en la construcción de la historia junto con el realizador. Por otro lado, en esta época comienzan a emitirse testimonios más breves y más variados. En los primeros años con una sola entrevista se construía muchas veces un reportaje. A partir de ahora será necesario incluir voces diferentes que den una mayor sensación de agilidad a la historia que se relata (Magro, 2003. Pág.62).

A lo largo de los primeros años de la Transición, y debido a la intensidad de los cambios políticos y sociales que se vivieron en España, este espacio informativo prestó especial interés a temas nacionales -aunque sin dejar de lado a los internacionales-, tratando de reflejar en sus reportajes los principales hitos de la democratización del país, tanto desde un punto de vista político como desde una perspectiva social.

En el siguiente apartado analizaremos el discurso que Informe Semanal desarrolló ante el primer aniversario de lo que, desde una perspectiva clásica, se consideran tres de los principales momentos claves que constituyeron la base política del cambio democratizador en España: proclamación de Juan Carlos de Borbón como Rey de 
España, nombramiento de Adolfo Suárez como presidente del Gobierno y las elecciones generales de junio de 1977.

\section{Las efemérides políticas narradas por Informe Semanal}

La Transición democrática comienza, tanto en el ámbito político como en el televisivo, a mediados de 1976 cuando llega a la presidencia del Gobierno Adolfo Suárez y este nombra a Rafael Ansón director de RTVE. En ese contexto de la "gran zancada" del inicio del cambio (Macía, 1981. Pág. 205) la cadena estatal celebró el primer aniversario de la proclamación del Rey Juan Carlos I. Para conmemorar esta efeméride, la pequeña pantalla puso en marcha unos contenidos televisivos y, como era de esperar, ante la magnitud de tal aniversario, Informe Semanal programó la emisión de un reportaje especial mucho más extenso de lo habitual (con casi media hora de duración) titulado Juan Carlos, Rey (TVE, emitido el 27 de noviembre de 1976).

Este espacio buscó acercar a los espectadores al lado más íntimo, y por lo tanto menos conocido, del Monarca. A través de un repaso cronológico, las anécdotas y el retrato del día a día fueron jalonando el contenido de este reportaje. El trasfondo político que llevaba implícito el aniversario de la entronización quedó diluido en la imagen amable y familiar que se quiso mostrar de la Corona y en la exaltación que el guión hizo en relación con el respaldo popular que esta institución tenía tras su primer año de existencia; un respaldo tan sumamente férreo y homogéneo que no resultaba demasiado acorde con la realidad social teniendo en cuenta que el proceso de Transición estaba dando sus primeros pasos y que el Rey aún no había podido ganarse el favor de sectores sociales que no eran muy partidarios de su posición en la Jefatura del Estado (Preston, 2003. Pág.360. Soto, 1998. Pág. 24).

Los telespectadores pudieron contemplar una reproducción de los hechos que acontecieron el día que Juan Carlos de Borbón fue proclamado Rey: la llegada de los presidentes de otras naciones y de las familias reales europeas, la organización de las salas de prensa en el Palacio de Congresos de Madrid, imágenes de la comitiva real y de la cálida acogida que le brindaban los ciudadanos, etc. Tras la salida, bajo palio, de los Reyes de la Iglesia de San Jerónimo El Real la comitiva acudió al Palacio de Oriente para saludar a las autoridades invitadas ${ }^{1}$.

Junto a las imágenes que rememoraban aquellos actos oficiales, Informe Semanal quiso también rendir homenaje al lado más íntimo del Rey. Con este fin, la audiencia pudo contemplar desde imágenes de la Reina charlando con su jardinero, hasta otros planos en los cuales se podía ver a Juan Carlos I haciendo deporte o a toda la familia cenando en la más estricta intimidad y como si de una familia española cualquiera se tratara.

En el mes de julio de 1977, este informativo semanal incluyó en su agenda la conmemoración del primer año de Adolfo Suárez en la presidencia del Gobierno (TVE, Gobierno de Suárez, emitido el 2 de julio de 1977). Con motivo de esta efemé- 
ride, los telespectadores pudieron ver todo un panegírico sobre el presidente en el que se resaltaron momentos determinantes de la Transición como las elecciones generales celebradas semanas atrás el 15 de junio. En relación a estos comicios, el reportaje acudió de nuevo a una imagen "despolitizada" de las votaciones, en el sentido de que su mera existencia ya era reveladora de la evolución democratizadora que había vivido el país y, por lo tanto, sin que fuera necesario tener en cuenta los votos obtenidos por cada partido, estos comicios ya representaban otro objetivo cumplido por Suárez, quien "se comprometió a ser gestor de la Transición y lo consiguió" (TVE, Gobierno de Suárez, emitido el 2 de julio de 1977). .

Informe Semanal aprovechó la ocasión para trazar un reportaje autorreferencial y resaltar al espectador la neutralidad con la que la cadena pública había desarrollado la campaña electoral del 77, logrando así el beneplácito de la prensa:

Durante toda la campaña la prensa destacó la neutralidad con que Radiotelevisión española había tratado las informaciones suministradas por los propios partidos. (...) Para garantizar la absoluta neutralidad se creó un comité en radio televisión española integrado por representantes de los distintos partidos políticos que velaron por la objetividad en el tratamiento de los temas e intervenciones de los diferentes representantes y líderes (TVE, Gobierno de Suárez, emitido el 2 de julio de 1977).

Al repasar el primer año de Suárez en el poder se hizo referencia a la legalización del Partido Comunista de manera fugaz al aludir a aquel "Sábado de Gloria" únicamente con una breve frase que da paso de inmediato a una alocución descontextualizada del presidente que en realidad corresponde al discurso televisado en el cual anunciaba que se presentaba a las elecciones de junio del 77 como miembro de UCD. En aquel mensaje televisado, como recordaba Informe Semanal, el presidente del Gobierno aceptó "por completo la responsabilidad de esta decisión", refiriéndose a la legalización del PCE, y explicó que ésta se fundaba "en dos principios básicos: el del realismo y el del patriotismo. Realismo, porque entiendo que no es buena política la que se basa en cerrar los ojos a lo que existe; patriotismo, porque el servicio que en estos momentos nos exige España es aclarar las reglas del juego y numerar a los participantes" (TVE, Gobierno de Suárez, emitido el 2 de julio de 1977).

El punto de partida del reportaje Gobierno de Suárez fue el secuestro de Oriol por parte de los GRAPO y la celebración del referéndum de la Ley para la Reforma Política; cuyo respaldo social suponía -como recuerda la voz en off haciendo referencia a la prensa extranjera- "una victoria del sentido común de los españoles" (TVE, Gobierno de Suárez, emitido el 2 de julio de 1977).

A lo largo del reportaje se rememoran los principales acontecimientos violentos que tuvieron lugar durante los primeros meses de la Transición protagonizados por grupos terroristas o agrupaciones radicales y se alude de forma ligera a la crisis económica por la que atravesaba el país. Pero tras ocuparse fugazmente de momentos críticos, como por ejemplo la conocida como Semana Negra, siempre se insertaba una alocución de Suárez o un texto en off en el que se resalta un paso positivo dado por parte del Gobierno o por la ciudadanía con el respaldo internacional. Es decir, 
recordando el propio guión del reportaje, frente al recuerdo de los momentos críticos siempre se destaca "la respuesta serena frente a los que (...) habían querido interrumpir el camino a la democracia" (TVE, Gobierno de Suárez, emitido el 2 de julio de 1977).

La gestión de Adolfo Suárez durante su primer año de mandato es sintetizada por Informe Semanal a través de la referencia a una cita del diario Nouvo journal: "El presidente del Gobierno español conduce prudentemente a su país hacia la democracia" (TVE, Gobierno de Suárez, emitido el 2 de julio de 1977).

Por último, habría que señalar que el discurso elaborado por este informativo para la citada efeméride ofrecía una imagen del cambio democrático como si este fuese un proceso ya concluido:

Un año difícil para España. Doce meses que, para los observadores más optimistas, estarían surcados de problemas insalvables han dejado el camino preparado para la culminación del proceso democrático iniciado en su día por Adolfo Suárez. El gabinete Suárez cumplió su objetivo máximo, se comprometió a ser gestor de la transición y lo consiguió (TVE, Gobierno de Suárez, emitido el 2 de julio de 1977).

Cuando en 1978 se cumplió el primer aniversario de las elecciones al Congreso y al Senado del 15 de junio de 1977, las primeras celebradas en España desde 1936, Informe Semanal se volcó en recordar aquella fecha tan significativa de la Transición. Sin embargo, quizá para no caer en reiteraciones en relación con el reportaje especial que emitió la cadena dos días antes titulado Especial 15 de junio. Un año de democracia (TVE, emitido el 15 de junio de 1978), el guión de este espacio se centró básicamente en tomar el pulso de la opinión pública para poder conocer cómo se percibía en el país el cambio democrático.

Su media hora de duración -de nuevo encontramos una extensión superior a la habitual en los reportajes de este programa- se articuló en torno a una sucesión de totales de representantes del mundo laboral (trabajadores y representante de la patronal y de los sindicatos), jurídico, artístico, sanitario, deportivo y universitario (docentes y estudiantes). Las declaraciones, encadenadas una de tras de la otra dejando las más negativas en los primeros minutos del reportaje, reprodujeron a los ojos del televidente la imagen de una opinión pública con tendencia a la homogenización, que aplaudía, en líneas generales, el camino recorrido desde esos primeros comicios. Los balances negativos -reservados mayormente para el inicio del reportaje- si bien desaprobaron aspectos o taras del sistema como ciertos posos fascistas, la falta de libertades, la precaria situación económica o la inseguridad ciudadana; en ningún caso arremetieron de forma directa contra la figura de Suárez o de UCD. Con lo cual, TVE conseguía difundir una imagen mediática de libertad de opinión y pluralidad, a la vez que lograba mantener al Gobierno al margen de la responsabilidad principal en relación a los problemas o cuestiones que eran objeto de críticas por parte de los ciudadanos a los que habían preguntado las cámaras de televisión; puesto que esas deficiencias eran, según la interpretación que ofrecía la voz en off, una tarea común que concernía a todos por igual ${ }^{2}$. 


\section{Conclusiones}

El hecho de detenernos a analizar el relato televisivo del primer aniversario de tres de los principales hitos políticos de la Transición y el hecho de hacerlo a través de un informativo de emisión semanal nos posibilita observar el tratamiento que dichas efemérides tan significativas recibieron en la cadena estatal en un espacio que por su formato, y por tratarse de reportajes que planteaban un balance retrospectivo, parece llamado a ofrecer un producto con más carga reflexiva que la que pudiera esperarse de cualquier otro formato informativo. Aunque el trabajo que se presenta es breve y no nos permite profundizar en el discurso televisivo, sí pretende ofrecer unas pistas de cuál fue el "relato oficial televisado" de la Transición a partir del discurso que la cadena estatal a través de Informe Semanal transmitió en relación al Rey, a Suárez y a las elecciones generales del 77 .

Estas efemérides conducían al espectador a la celebración de un "ritual sagrado", un "acto simbólico", en el sentido desarrollado por Dayan y Katz (1995) -aunque no fuesen emisiones en directo-, que impregnaba de grandeza a la significación de dicho acontecimiento rememorativo. Estos reportajes, introducidos en la agenda mediática con motivo de la celebración del primer aniversario de la coronación del Rey, del nombramiento de Suárez como presidente o de las primeras elecciones de la Transición cumplieron con "la función conmemorativa" propia de las transmisiones de la "historia en directo" y perseguían como objetivo principal recordar al espectador "lo que merece ser recordado" (Dayan y Katz, 1995).

Además, la narración en la pequeña pantalla de estas efemérides buscó no sólo trazar una retrospectiva laudatoria de los doce meses que habían transcurrido sino también llevar a cabo una socialización del recuerdo (Burke, 2000) y conformar una memoria colectiva con la ayuda de la capacidad instrumental que tiene la televisión de producir (y reproducir) una "historia popular" (Edgerton, 2001).

A la hora de trazar la valoración del primer año transcurrido desde estos tres hitos, los guiones de Informe Semanal optaron por la inclusión de elementos argumentales con valor positivo. De esta manera, este espacio, y por extensión Televisión Española, desenvolvió toda una estrategia mediática que le llevó a convertirse en una instancia, en un principio, testificadora y, posteriormente, productora de la memoria colectiva de la historia más reciente. Este imaginario público, conformado a través de la socialización del recuerdo, contribuía a la legitimación del proceso y, por lo tanto, favorecía la evolución de la Transición según la línea marcada por sus dirigentes.

La fe en la Transición que irradiaban los reportajes de Informe Semanal y la imagen de normalidad absoluta que reflejaban sus emisiones se transmitieron a la par que se dejaba constancia, aunque de manera vaga, de las acciones violentas de los grupos terroristas o de las organizaciones de extrema derecha y de las consecuencias de la profunda crisis económica. Frente a esta realidad, Informe Semanal trató de hacer llegar al telespectador un mensaje de serenidad y de confianza en la instauración de la democracia; buscando, finalmente, la reunificación de la opinión pública alrededor de fundamentos democráticos y pacifistas. 
Por otra parte, los contenidos que reflejaban la imagen del cambio que promocionaba el Gobierno se transformaron, al mismo tiempo, en una representación simbólica de lo que debía ser la sociedad en el nuevo régimen. La clave estaba en que los telespectadores recibieran en sus hogares el mensaje de que la democracia, desde el día en el que nació la monarquía de Juan Carlos I y gracias a las directrices emanadas desde el Estado, no era una promesa que podía cumplirse sino una realidad.

\section{Bibliografía}

Burke, P. (2000). Formas de historia cultural. Madrid: Alianza.

Dayan, D., and Katz, E. (1995). La historia en directo. La retransmisión televisiva de los acontecimientos. Barcelona: Gustavo Gili.

Edgerton, G. R. (2001). "Television as historian. A different kind of history altogether". En Gary R. Edgerton and Peter C. Rollins (eds.). Television Histories. Shaping Collective Memory in the Media Age. Lexington: Kentucky University Press.

Macía, P. (1981). Televisión hora cero. Madrid: Erisa.

Magro, B. (2003). Informe Semanal. 30 años de historia. Barcelona: Plaza \& Janés.

Martín Jiménez, V. (2013). Televisión España y la Transición democrática. La comunicación politica del Cambio (1976-1979). Valladolid: Ediciones Universidad de Valladolid.

Preston, P. (2003). Juan Carlos. El Rey de un pueblo. Madrid: Plaza y Janés.

Soto, A (1998). La transición a la democracia. España, 1975-1982. Madrid: Alianza Editorial.

\section{Notas}

1 La revista Tele-Radio también dedicó una edición especial al aniversario de la coronación. El reportaje "El Pueblo y la Corona" recuerda mucho al trabajo de Informe Semanal que estamos analizando en estas páginas. Tele-Radio, $\mathrm{n}^{\circ}$ 987, 22-28 de noviembre de 1976, pp. 3-10.

2 Durante el reportaje, además de gente anónima -obreros, estudiantes, viandantes- la audiencia pudo conocer la opinión de personas conocidas de diferentes ámbitos: Aurora Bautista, Concha Velasco, Ángel Nieto, Máximo, Conchita Montes, Juan José Linz, Peridis, Marcelino Camacho, etc.

\section{La autora}

Virginia Martín Jiménez es Doctora y Licenciada en Historia del Periodismo y actualmente trabaja como profesora y peridismo en la Universidad de Valladolid. 